JMI Vol. 40 No. 1 Juni 2018

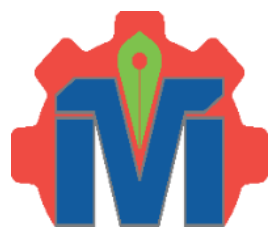

METAL INDONESIA

Journal homepage:

http://www.jurnalmetal.or.id/index.php/jmi

p-issn: $0126-3463$

e-issn : 2548-673X

\title{
STUDI AWAL SOLVENT DEBINDING FEEDSTOCK METAL INJECTION MOLDING Fe2\% Ni
}

\section{A PRELIMINARY STUDY ON THE SOLVENT DEBINDING OF Fe2\%Ni FEEDSTOCK IN METAL INJECTION MOLDING PROCESS}

\author{
Winda Sri Jaman, Shinta Virdhian, Eva Afrilinda \\ Balai Besar Logam dan Mesin Jl. Sangkuriang No. 12 Bandung \\ Email: windasj@yahoo.com
}

\begin{abstract}
Abstrak
Metal Injection Molding (MIM) merupakan proses manufaktur yang mempunyai 4 tahapan proses utama yaitu mixing, injection, debinding dan sintering. Solvent debinding adalah salah satu cara menghilangkan polimer dari serbuk logam (feedstock). Kelebihan dari solvent debinding ini adalah larutan yang digunakan dapat di daur ulang sehingga mengurangi biaya produksi produk MIM. Penelitian ini diperlukan untuk memenuhi kebutuhan industri dan memperkaya proses-proses debinding dengan berbagai larutan (solvent) kimia. Studi awal solvent debinding pada feedstock $\mathrm{Fe} 2 \% \mathrm{Ni}$ hanya dibatasi untuk menghilangkan binder jenis paraffin wax, karena penggunaannya hampir di setiap feedstock MIM terdapat paraffin wax. Feedstock dilarutkan dan direndam menggunakan larutan ethanol, n-hexane, heptana dengan parameter waktu 2,3,4 jam dan temperatur $40,45,50^{\circ} \mathrm{C}$ untuk ethanol dan n-hexane, heptana dengan temperatur 50,55 dan $60^{\circ} \mathrm{C}$. Ditimbang kehilangan berat feedstock dari masing-masing para mater yang telah dilarutkan dan di keringkan pada temperatur $30^{\circ} \mathrm{C}$. Kelarutan ethanol terhadap kehilangan berat terendah $0,53 \%$ dan kehilangan berat tertinggi $1,70 \%$. Kelarutan n-hexane terhadap kehilangan berat terendah $4,14 \%$ dengan kehilangan berat tertinggi pada $4,55 \%$. Kelarutan heptana terhadap kehilangan berat tertinggi dibandingkan dengan ethannol dan n-hexane, kehilangan berat terendah 3,40\% dan kehilangan berat tertinggi 9,74\% . Kondisi feedstock yang sudah di debinding terlihat masih terdapat sisa-sisa binder selain paraffin wax, keragaman bentuk pada serbuk menjadikan kehomogenan pada feedstock.
\end{abstract}

Kata kunci: Solvent Debinding, Ethanol, n-Hexane, Heptana

\begin{abstract}
Metal Injection Molding (MIM) is a manufacturing process that has 4 main process stages: mixing, injection, debinding and sintering. Solvent debinding is one way to remove polymers from metal powders (feedstock). The advantages of this solvent debinding is that the solution used can be recycled thereby reducing the cost of producing MIM products. This research is needed to meet the needs of industry and enrich the processes of debinding with various chemical solutions (solvent). The initial study of solvent debinding in the Fe $2 \%$ Ni feedstock is limited only to remove paraffin wax type binders, because of its use in almost every MIM feedstock there is paraffin wax. The feedstock was dissolved and immersed using ethanol, n-hexane, heptane solution with a time parameter of 2,3,4 hours and temperature of $40,45,50^{\circ} \mathrm{C}$ for ethanol and n-hexane, heptane with temperature 50,55 and $60^{\circ} \mathrm{C}$. Weighed by loss of feedstock weight from each of the dissolved mater and dried at $30^{\circ} \mathrm{C}$. The solubility of ethanol to the lowest weight loss was $0,53 \%$ and the highest weight loss was $1,70 \%$. The solubility of n-hexane to the lowest weight loss was 4,14\% with the highest weight loss at 4,55\%. The solubility of heptane to the highest weight loss was compared with ethannol and n-hexane, when the lowest weight loss was 3,40\% and the highest weight loss was 9,74\%. Feedstock conditions that have been in the debinding is still visible remains of binders other than paraffin wax, the diversity of shapes on the powder to make homogeneity on the feedstock.
\end{abstract}




\section{PENDAHULUAN}

Metal Injection Molding adalah proses produksi produk logam yang mempunyai 4 proses tahapan utama, yaitu : mixing (serbuk+polimer+aditif) untuk memproduksi bahan baku yang dinamakan feedstock, injection molding, debinding dan sintering. Debinding adalah prosespemisahan binder (polimer + aditif) dari feedstock (gambar 1). ${ }^{4}$ Debinding terbagi menjadi:

1. Larutan (solvent) debinding

2. Thermal debinding

3. Catalytic debinding

4. Dan jenis-jenis debinding lainnya. ${ }^{1,2}$

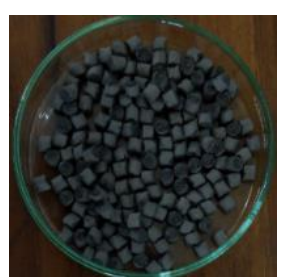

Gambar 1. Feedstock Fe2\%Ni (Serbuk+Binder)

Proses debinding merupakan parameter yang menentukan kualitas hasil produk (brown part) dari proses Metal Injection Molding. Solvent debinding adalah proses menghilangkan polimer+wax+aditif dengan larutan kimia (gambar 2). ${ }^{8,9}$ Kelebihan dari proses ini adalah larutan dapat digunakan kembali setelah di distilasi (dibersihkan) untuk proses selanjutnya. Penentuan temperatur debinding dan temperatur larutan (solvent) yang tepat akan menghasilkan penghilangan binder yang maksimal.

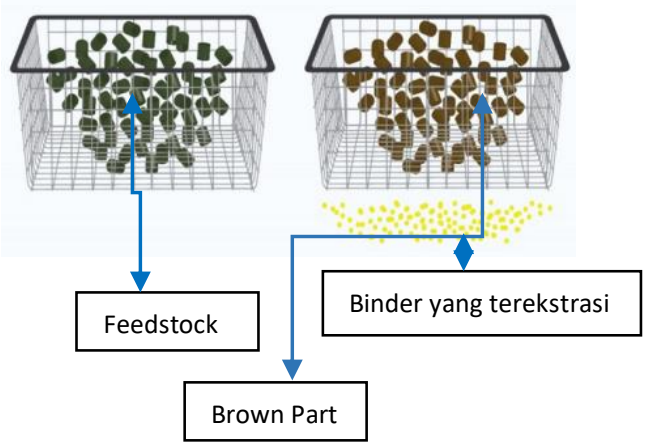

Gambar 2. Feedstock dan Brown Part (Feedstock setelah debinding) $^{5}$ hexane dan heptan, merupakan pelarut yang ramah lingkungan dan merupakan pelarut organik yang non ozone depleting juga rendah/mengurangi biaya investasi. ${ }^{1}$ Jenis larutan (solvent), temperatur dan waktu debinding adalah parameter yang berpengaruh pada proses ini. ${ }^{1}$ Pada penelitian ini dilakukan untuk mengetahui kehilangan berat parafin wax dari feedstock $\mathrm{Fe} 2 \% \mathrm{Ni}$ terhadap parameter waktu dan beberapa jenis larutan (solvent). Kandungan feedstok ini terdiri dari $59 \%$ volume $\mathrm{Fe} 2 \% \mathrm{Ni}$ dan $41 \%$ volume binder (polimer+paraffin wax+aditif).

Sifat dari larutan larutan pada proses debinding MIM harus tidak reaktif terhadap serbuk logam, melarutkan binder, memiliki titik didih yang tepat dan mudah dihilangkan pada saat akhir reaksi pada feedstock Fe2\%Ni. Larutan organik pada umumnya bersifat non polar dan parafin wax bersifat non polar, dimana senyawa non polar dapat larut dalam air dan pelarut lainnya. Senyawa ini terbentuk akibat adanya suatu ikatan elektron pada unsur-unsur yang membentukya karena unsur yang berkaitan mempunyai nilai elektronegatifitas yang sama/hampir sama.

\section{BAHAN DAN METODOLOGI}

Bahan feedstock $\mathrm{Fe} 2 \% \mathrm{Ni}$ dengan berat awal@5gr $( \pm 0,5$ gr $)$ dan larutan (solvent) ethanol, n-hexane dan heptan @ 150 ml. Metoda extrasi yang digunakan adalah ektrasi panas, pengukuran berat awal dan berat akhir akan dianalisa secara kuantitatif, sehingga menghasilkan berat binder yang sudah hilang/ terektrasi/terpisah/terlarut, pada gambar 3 menjelaskan tentang tahapan pengerjaan penelitian ini.

Larutan (solvent) debinding dengan menggunakan pelarut organik ethanol, 


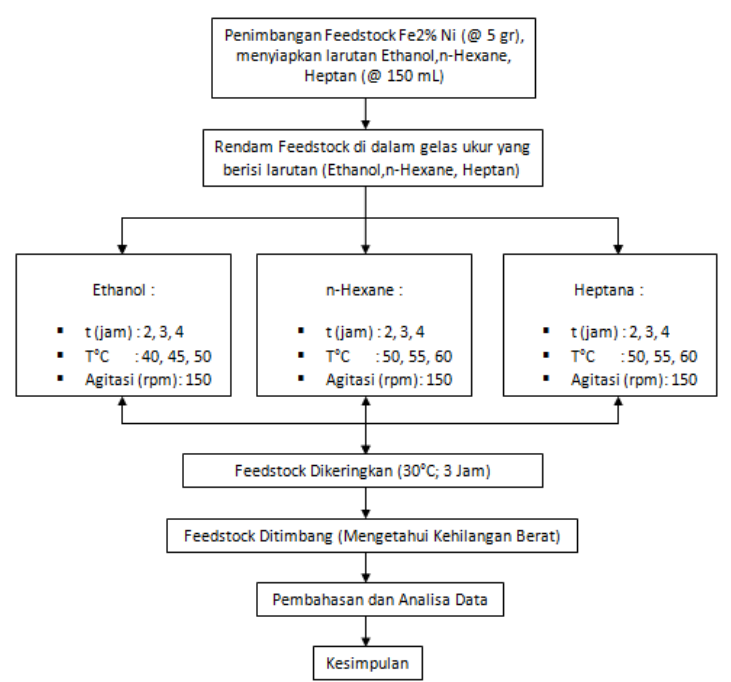

Gambar 3. Metodologi penelitian

Pada gambar 4 menunjukkan penelitian solvent debinding berlangsung, masing-masing feedstock yang sudah ditimbang 5 gr kemudian disimpan dikeranjang dan direndam pada solvent yang sudah terisi dalam gelas ukur sebanyak $150 \mathrm{ml}$. Parameter waktu yang diaplikasikan pada setiap percobaan adalah 2,3, dan 4 jam. Parameter temperatur yang diaplikasikan 40,45 dan $50^{\circ} \mathrm{C}$ pada ethanol, nhexane dan heptan pada temperatur 50,55 dan $60^{\circ} \mathrm{C}$, diagitasi pada kecepatan @ $150 \mathrm{rpm}$.
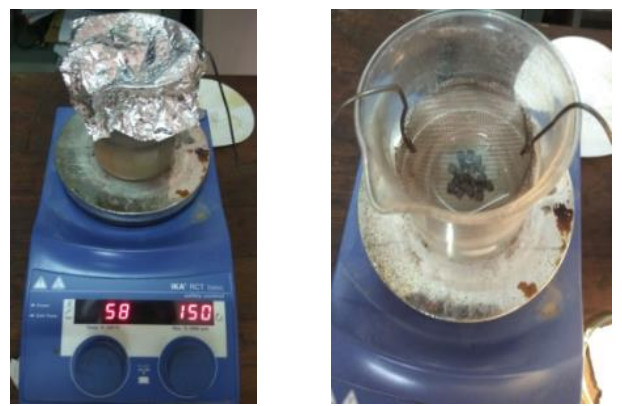

Gambar 4. Proses Solvent Debinding

\section{HASIL DAN PEMBAHASAN}

Binder akan terpisah dari feedstock karena terlarut dalam larutan ethanol, n-hexane dan heptan. Mekanisme ini terjadi akibat adanya gaya kapilaritas dan gradien konsentrasi antara binder pada brown part (serbuk logam) dan larutan. Maka mekanisme difusi akan terjadi, mengalirnya atau berpindahnya suatu zat dalam pelarut dari bagian berkonsentrasi tinggi ke bagian yang berkonsentrasi rendah, maka binder akan mengalir diantara rongga-rongga serbuk menuju permukaan feedstock (gambar 5). Feedstock direndam ke dalam larutan, binder utama akan mulai mencair maka kecepatan disolusi lebih cepat daripada kondisi solid state. $^{1}$

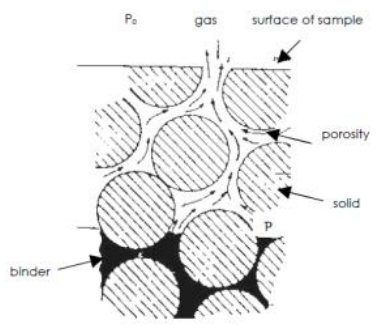

Gambar 5. Proses Debinding 6

Data pada tabel 1 menunjukkan hasil ekstrasi feedstock dengan larutan ethanol, perubahan nilai kehilangan berat yang diakibatkan oleh kenaikan waktu dan temperatur selama proses debinding berlangsung pada penelitian ini. Kehilangan berat terendah pada temperatur $40^{\circ} \mathrm{C}$ dengan waktu 2 jam dengan nilai $0,53 \%$. Kehilangan berat tertinggi pada temperatur $50^{\circ} \mathrm{C}$ dengan waktu 4 jam dengan nilai $1,70 \%$.

Tabel 1. Kehilangan berat pada larutan ethanol

\begin{tabular}{|c|c|c|c|}
\hline \multirow{2}{*}{ ETHANOL } & \multicolumn{3}{|c|}{ Temperatur $\left({ }^{\circ} \mathrm{C}\right)$} \\
\cline { 2 - 4 } & 40 & 45 & 50 \\
\hline Waktu (Jam) & \multicolumn{3}{|c|}{ Kehilangan Berat (\%) } \\
\hline 2 & 0,53 & 0,89 & 1,04 \\
\hline 3 & 0,70 & 0,85 & 1,03 \\
\hline 4 & 0,67 & 0,97 & 1,70 \\
\hline
\end{tabular}

Data pada tabel 2 menunjukkan hasil ekstrasi feedstock dengan larutan n-hexane, perubahan nilai kehilangan berat yang diakibatkan oleh kenaikan waktu dan temperatur selama proses debinding berlangsung. Kehilangan berat terendah pada temperatur $50^{\circ} \mathrm{C}$ dengan waktu 3 jam dengan nilai $4,14 \%$. Kehilangan berat tertinggi pada temperatur $60^{\circ} \mathrm{C}$ dengan waktu 4 jam dengan nilai $4,55 \%$. 
Tabel 2. Kehilangan berat pada larutan nhexane

\begin{tabular}{|c|c|c|c|}
\hline \multirow{2}{*}{ n-HEXANE } & \multicolumn{3}{|c|}{ Temperatur $\left({ }^{\circ} \mathrm{C}\right.$ ) } \\
\cline { 2 - 4 } & 50 & 55 & 60 \\
\hline Waktu (Jam) & \multicolumn{3}{|c|}{ Kehilangan Berat (\%) } \\
\hline 2 & 4,33 & 4,40 & 4,51 \\
\hline 3 & 4,14 & 4,45 & 4,51 \\
\hline 4 & 4,43 & 4,50 & 4,55 \\
\hline
\end{tabular}

Data pada tabel 3 menunjukkan hasil ekstrasi feedstock dengan larutan Heptana, perubahan nilai kehilangan berat yang diakibatkan oleh kenaikan waktu dan temperatur selama proses debinding berlangsung. Kehilangan berat terendah pada temperatur $50^{\circ} \mathrm{C}$ dengan waktu 3 jam dengan nilai $3,40 \%$. Kehilangan berat tertinggi pada temperatur $60^{\circ} \mathrm{C}$ dengan waktu 2 jam dengan nilai $9,74 \%$.

Tabel 3. Kehilangan berat pada larutan heptana

\begin{tabular}{|c|c|c|c|}
\hline \multirow{2}{*}{ HEPTAN } & \multicolumn{3}{|c|}{ Temperatur $\left({ }^{\circ} \mathrm{C}\right.$ ) } \\
\cline { 2 - 4 } & 50 & 55 & 60 \\
\hline Waktu (Jam) & \multicolumn{3}{|c|}{ Kehilangan Berat (\%) } \\
\hline 2 & 4,42 & 4,67 & 9,74 \\
\hline 3 & 3,40 & 4,40 & 4,53 \\
\hline 4 & 5,46 & 4,45 & 4,50 \\
\hline
\end{tabular}

Pada gambar 6,7 dan 8 media larutan menunjukkan kenaikan kehilangan berat binder akibat dari kenaikan temperatur dan waktu. Proses difusi berlangsung dengan meningkatnya ketidakterarutan kisi-kisi akibat kenaikan temperatur, waktu dan gradient konsentrasi.

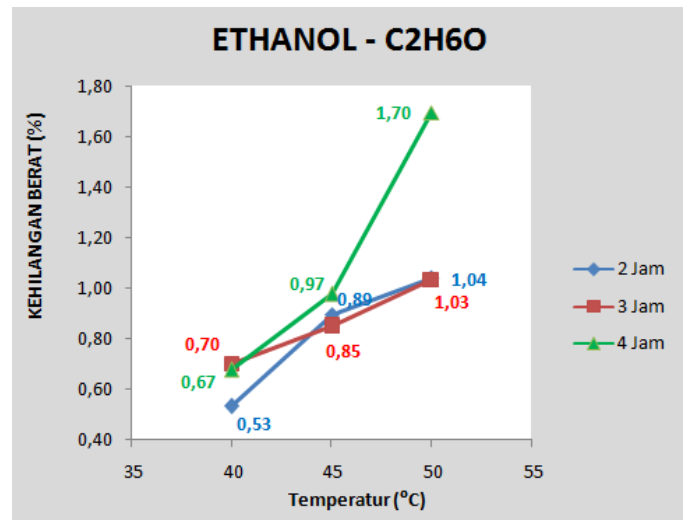

Gambar 6. Kehilangan berat terhadap temperatur dan waktu pada larutan ethanol

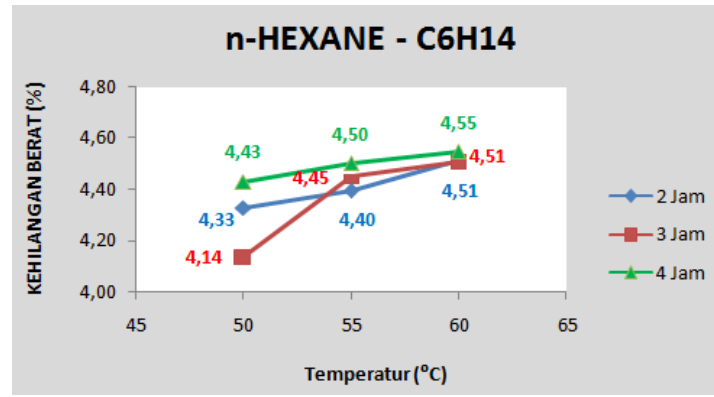

Gambar 7. Kehilangan berat terhadap temperatur dan waktu pada larutan n-hexane

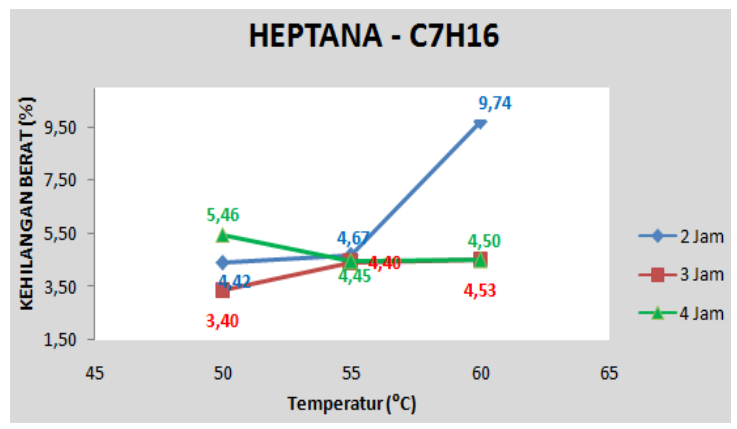

Grafik 8. Kehilangan berat terhadap temperatur dan waktu pada larutan heptane

Kecenderungan gambar grafik dari ketiga larutan ini (gambar 6,7,8) mempunyai kecenderungan/pola kenaikan nilai kehilangan berat yang diakibatkan oleh kenaikan temperatur, waktu dan gradient konsentrasi. Sesuai dengan Hukum Fick kedua bahwa perubahan konsentrasi terhadap waktu dalam media tertentu adalah sebanding dengan perubahan dalam konsentrasi pada sistem tersebut.

Kemampuan berdifusi dari heptana terhadap binder menjadi optimum karena memiliki kesamaan sifat-sifat non polar. Ada 3 hal yang mempengaruhi kepolaran dari larutan (solvent) adalah nilai momen dipol, konstanta dielektrik dan kelarutan dengan air. Semakin rendah nilai momen dipol dan konstanta dielektrik rendah makan sifatnya semakin non polar dan sebaliknya.$^{3}$

Hal ini disebabkan oleh prinsip "like dissolve like"(saling melarutkan antara reangent dan reaktan) karena heptana dan parafin wax sama-sama bersifat non polar, larutan (solvent) yang mempunyai sifat non polar memiliki kelarutan yang lebih besar untuk polimer non polar. ${ }^{3,10}$ Bisa dilihat juga dari bentuk struktur kimia dari heptana 
berbentuk simetris dan mempunyai ikatan hidrogen yang lemah/rendah. ${ }^{8,9,10}$

\section{HASIL SEM}

Keragaman bentuk dan ukuran serbuk yang spherical dan irregular terlihat pada gambar 9. Dengan keragaman bentuk serbuk ini akan memberikan efek positif terhadap kehomogenan bentuk dan ikatan antara serbuk +binder dan menjadi high packing density.

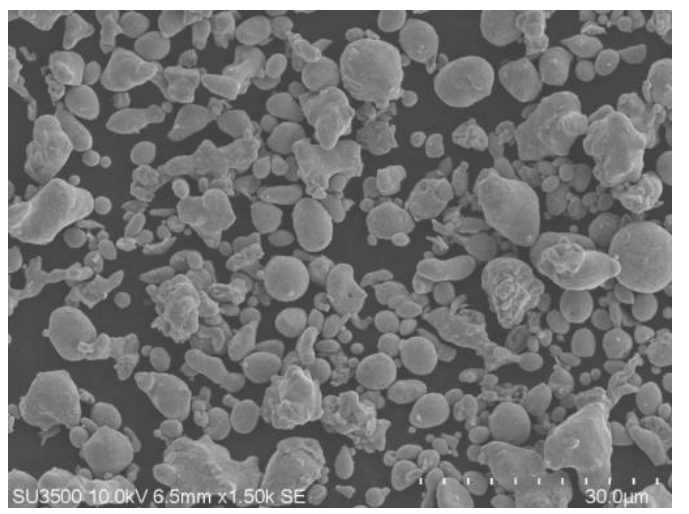

Gambar 9. Karakterisasi SEM serbuk logam $\mathrm{Fe} 2 \% \mathrm{Ni}$

Karakterisasi SEM pada gambar 9 dilakukan sebelum serbuk logam dibuat menjadi feedstock, perbedaan antara serbuk logam yang sudah dibuat feedstock (ditambahkan binder) akan terlihat jelas. Serbuk logam yang sudah dibuat feedstock akan terselimuti oleh binder dan berikatan satu dengan yang lainnya setelah melalu proses kneading dan mixing dan peletizing.

Pada gambar 10 adalah hasil karakterisasi SEM pada sample feedstock yang sudah diekstrasi larutan ethanol dengan kehilangan berat tertinggi $1,70 \%$ pada temperatur $50^{\circ} \mathrm{C}$ dan waktu 4 jam. Sebagai contoh pada lingkaran merah menunjukkan permukaan serbuk logam yang masih tertutupi oleh binder, permukaan masih terlihat kasar dan tebal, pori-pori binder hanya terbuka sedikit. Lingkaran hijau dan ungu menunjukkan ikatan antara binder yang masih banyak, tebal dan bertumpuk mengikat antara serbuk logam yang satu dengan yang lainnya.

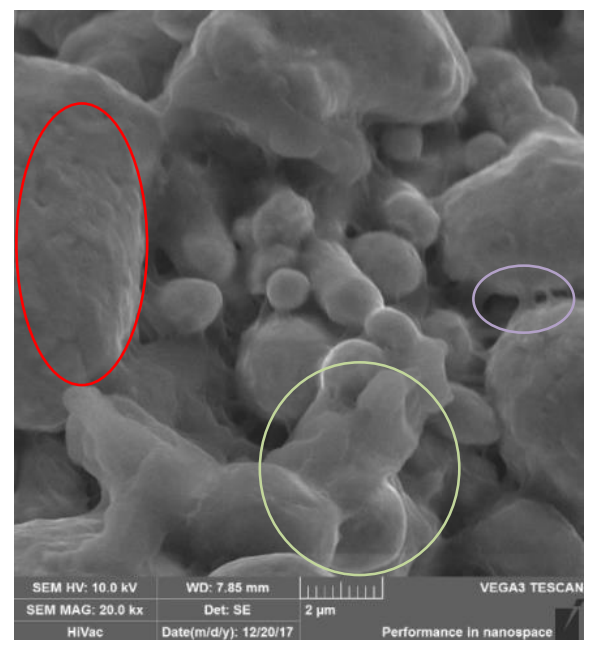

Gambar 10. Karakterisasi SEM Feedstock setelah di debinding ethanol

Pada gambar 11 adalah hasil karakterisasi SEM pada sample feedstock yang sudah diekstrasi larutan n-hexane dengan kehilangan berat tertinggi $4,55 \%$ pada temperatur $60^{\circ} \mathrm{C}$ dan waktu 4 jam. Sebagai contoh pada lingkaran merah menunjukkan permukaan serbuk logam yang masih tertutupi oleh binder, permukaan masih lebih kasar dan tebal, pori-pori binder sudah terbuka banyak. Lingkaran hijau dan ungu menunjukkan ikatan antara binder yang banyak, tetapi sudah lebih tipis walaupun bertumpuk dan masih mengikat antara serbuk logam yang satu dengan yang lainnya.

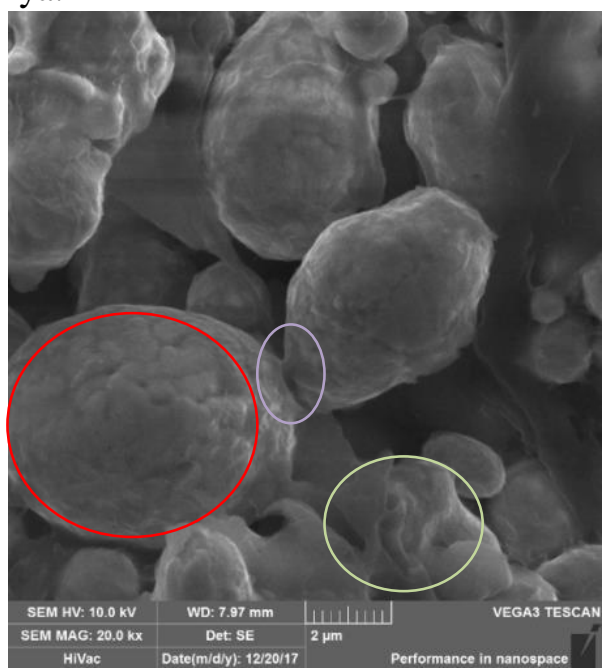

Gambar 11. Karakterisasi SEM feedstock setelah di debinding n-Hexane 
Pada gambar 12 adalah hasil karakterisasi SEM pada sample feedstock yang sudah diekstrasi larutan heptane dengan kehilangan berat tertinggi $9,74 \%$ pada temperatur $60^{\circ} \mathrm{C}$ dan waktu 2 jam. Sebagai contoh pada lingkaran merah menunjukkan permukaan serbuk logam yang masih tertutupi oleh sisa binder, permukaan masih terlihat lebih kasar dan tipis, pori-pori binder hanya terbuka sangat banyak. Lingkaran hijau dan ungu menunjukkan ikatan antara binder yang sedikit, tipis dan tidak bertumpuk, masih mengikat antara serbuk logam yang satu dengan yang lainnya tetapi tidak di semua area permukaan serbuk.

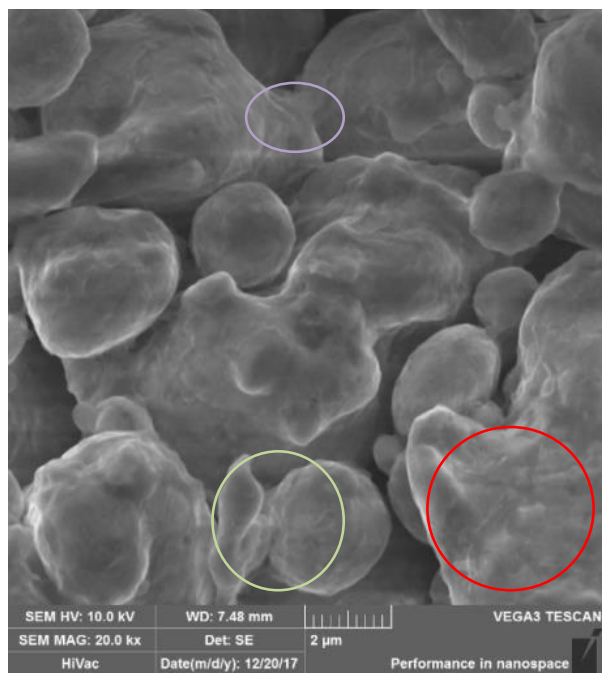

Gambar 12. Karakterisasi SEM feedstock setelah di debinding heptane

\section{KESIMPULAN}

Dari ketiga jenis larutan (solvent) yang mempunyai kondisi optimum untuk mengekstrasi atau menghilangkan binder (jenis paraffin wax) adalah heptana dengan parameter waktu 2 jam, temperatur $60^{\circ} \mathrm{C}$ dengan kehilangan berat $9,74 \%$.

Kemampuan berdifusi pada penelitian ini sangat dipengaruhi oleh kenaikan temperatur dan waktu, sehinga persyaratan Hukum Ficks terpenuhi.

Karakterisasi feedstock dengan SEM menunjukkan masih adanya sisa binder selain paraffin wax, terlihat adanya ikatan binder disekeliling serbuk logam. Secara kasat mata dapat terlihat pula kehomogenan dan bervariasinya bentuk serbuk yang sesuai dengan persyaratan serbuk untuk MIM. ${ }^{1,2}$

\section{DAFTAR PUSTAKA}

1. Donald F. Heaney; HANDBOOK OF METAL INJECTION MOLDING; ISBN 978-0-85709-066-9 (print); ISBN 978-0-85709-623-4 (online); Published by Woodhead Publishing Limited,80 High Street, Sawston, Cambridge CB22 $3 \mathrm{HJ}$, ;www.woodheadpublishing.com; www.woodheadpublishingonline.com

2. Randall M. German; METAL INJECTION MOLDING- A COMPREHENSIVE MIM DESIGN GUIDE; Donald F. Heaney; HANDBOOK OF METAL INJECTION MOLDING; ISBN 978-0-85709-066-9 (print); Metal Powder Industries Federation Princeton, New Jersey 08540; Publish 2011

3. Fetra Esatika; Harsyatria Fitrio; Prof. Dr. Ir. Gede Wibawa, M. Eng; SOLUBILITAS EMPAT MACAM PELARUT ORGANIK MASINGMASING DALAM EMPAT POLIMER MENGGUNAKAN METODE PIEZOELECTRIC QUARTZ CRYSTAL MICROBALANCE;

LaboratoriumThermodinamika Teknik Kimia FTI-ITS

4. R. Asmawi; M.H.I Ibrahim; A. M. ; N. Mustafa; SOLVENT DEBINDING OF MIM PARTS IN A POLYSTYRENEPALM OIL BASED BINDER SYSTEM; IOP Conf. Series: Materials Science and Engineering 160 (2016) 012063 doi:10.1088/1757899X/160/1/012063; International Engineering Research and Innovation Symposium (IRIS)

5. Dynacast; Solution Made Solid; 14.04.WIB;19/11/2017;https://www.dyn acast.com/the-mim-process

6. Friedherz H. Becker; Riedhammer $\mathrm{GmbH}$; Debinding Process; Klingenhofstrasse 72; 90411 Nürnberg; $13.28 \quad$ WIB; $19 / 11 / 2017$; 
http://www.riedhammer.de/System/00/0 1/42/14224/633776345920000000_1.pdf

7. Muhammad Ilman Hakimi Chua; Abu Bakar Sulong; Mohd Fazuri Abdullah; Norhamidi Muhamad ; OPTIMIZATION OF INJECTION MOLDING AND SOLVENT DEBINDING PARAMETERS OF STAINLESS STEEL POWDER (SS3161) BASED FEEDSTOCK FOR METAL INJECTION MOLDING; SAINS MALAYSIANA 42(12)(2013; 1743-1750

8. Jean-Michel Guenet; POLYMERSOLVENT MOLECULAR COMPOUND; Elsevier; ISBN-13: 9780-08-045144-2; Linacre House; Jordan Hill, Oxford OX2 8DP; UK Radarweg
29; PO Box 211; 1000 AE Amsterdam; The Netherlands; First edition 2008

9. D.W. VAN KREVELEN; K. TE NIJENHUIS; PROPERTIES OF POLYMER; Elsevier; ISBN978-0-08054819-7; Radarweg 29, PO Box 211, 1000 AEAmsterdam, The Netherlands; Linacre House, Jordan Hill, OxfordOX2 8DP,UK

10. Beth A. Miller-Chou; Jack L. Koenig; A REVIEW OF POLYMER DISSOLUTION; Elsevier; Prog. Polym. Sci. $28 \quad$ (2003) 1223-1270; www.elsevier.com/locate/ppolysci 